\title{
Higiene Bucal: mudanças de conhecimentos e hábitos de uma geração para outra em uma população de baixa renda
}

\author{
Oral Hygiene: changes of knowledge and habits from a \\ generation to another in a low-income population
}

Luiz Fernando Zoch Lopes* Dra. Maria Celeste Morita*:

LOPES, L. F. Z; MORITA, M. C. Higiene Bucal: Mudanças de Conhecimentos e Hábitos de uma Geração para Outra em uma População de Baixa Renda. Semina, Londrina, v. 18, ed. cspecial, p. 25-33, fev. 1997.

RESUMO: A cárie dentária vem sofrendo um nitido declínio na população Londrinense. Nos paises desenvolvidos, o uso de dentifricios fluoretados pode ser considerado como o único denominador comum àqueles que apresentaram declínio de prevalência de cárie. No Brasil, informações sobre o impacto que a fluoretação dos principais dentifricios vendidos no mercado pode ter causado no perfil epidemiológico, bem como o alcance dessa medida em população de baixa renda, não estão disponiveis.

No presente estudo, em uma população de baixa renda, na região sul do municipio de Londrina, foram entrevistadas 39 crianças e suas respectivas mães, com o objetivo de verificar o conhecimento desta população em relação à higiene bucal, bem como analisar a diferença de conhecimento entre as duas gerações (mães e filhos). As questões aplicadas através de questionário, na escola para os filhos e em visitas domiciliares para as mães, eram referentes a limpeza bucal, uso de escovas dentais, uso de denifificios, número de escovações diárias, tempo de higienização e orientações recebidas. Os resultados mostram una diferença significativa de conhecimento e de comportamento entre as duas gerações. As crianças escovam por mais tempo, um maior número de vezes ao dia e têm mais acesso a informação, quer seja através do dentista, da escola, da televisão ou das próprias mães. As mães, ao contrário, escovam menos e por um menor período de tempo e parecem estar sendo negligenciadas neste sentido, pois $61.53 \%$ das mães entrevistadas afirmaram que jamais receberam qualquer tipo de informação sobre higiene bucal.

* Autor: Aluno do $5^{\circ}$ ano de Graduação em Odontologia da Universidade Estadual de Londrina.

:* Orientadora: Mestre, Doutora en Saúde Pública, Prof Adjunto de Odontologia Social e Preventiva da Universidade Estadual de Londrina/Centro de Ciêneias da Saúde-

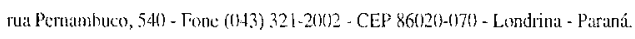




\section{PALAVRAS-CHAVE: Higiene Bucal; Cárie Dentária/Prevenção \& Controle; Escovação Dentária - Fatores Sócio-Econômicos.}

ABSTRACT: The dental caries have declined remarkably among the population of Londrina. In the developed countries, the use of fluoridated dentifrice (toothpaste) can be considered as the only common factor amongst the countries that showed a decline of caries prevalence. In Brazil, information about the impact fluoridation of the main dentifrice (toothpaste) sold in the market may have caused on the epidemiological profile as well as the extent of this measure on low-income population, are not available. In the present stuay, from a low-income population in the southern region of Londrina, 39 children, together with their mothers were interviewed with the purpose of verifying the knowledge held between the two generations (mothers and children). The questions applied by means of a questionnaire were about dental cleaning, use of toothbrushes, use of toothpaste, number of daily toothbrushing, period of time for hygiene and orieniations received. The results show a significant difference of knowledge as well as of behaviour between the two generations. The children brush their teeth for a long period of time, more often every doy and care more well-informed by the dentist, the school, the television or their own mothers. Their mothers, on the other hand, brush their teeth less and for a shorter period of time, besides being more careless concerning this subject, for $61,53 \%$ of the interviewed mothers stated that they never received any kind of information about dental hygiene.

KEY WORDS: Toothbrushing; Dental Caries/Prevention \& Control; Oral Hygiene; Quality of Life.

\section{INTRODUÇÃO}

A Odontologia moderna está praticamente toda voltada para a prevenção. Este fato não poderia ser diferente frente a evolução da ciência que traz consigo uma bagagem cientifica suficiente para permitir a afirmação que, nos dias atuais, é perfeitamente possível evitar-se as duas enfermidades mais prevalentes da cavidade bucal: a doença periodontail e a cárie.

As associações de classe têm procurado aplicar os conhecimentos preventivos, assim como transmiti-los às populações dos seus respectivos países. Entretanto, estes procedimentos não são tão simples ou fáceis nas suas aplicabilidades, principalmente num país como o nosso, onde a renda individual é uma das mais baixas do Mundo, o que, por sua vez, reflete nos problemas sociais e culturais (TODESCAN, 1991) 14 .
Sabemos que os usos e costumes da higiene bucal estão vinculados à cultura, condições sociais e fatores psicológicos individuais. A possibilidade ou não de mudança nos costumes ou nos hábitos está diretamente relacionada com a motivação e conscientização da população pelo Cirurgião Dentista e também através do marketing das indústrias (TODESCAN, 1991) ${ }^{15}$.

O flúor é um agente extensivamente comprovado como eficaz para a prevenção da doença cárie e é também um dos produtos químicos mais estudados na Odontologia nos últimos anos. A sua divulgação entre os profissionais de Odontologia é amplamente garantida, devendo este conhecimento ser transmitido à população (SERRA e CURY, 1992) ${ }^{11}$.

Hoje, a adição de flúor na água de abastecimento é uma pratica bastante comum e que tem sua eficácia comprovada. Deve-se salientar o fato de que a 
fluoretação da água de um município é um método adequado, pois beneficia todas as crianças sem distinção; eficiente, pois diminui a incidência de cárie; seguro, porque a proporção utilizada não produz nenhum efeito tóxico; econômico, pois custa um preço ínfimo por pessoa por ano; prático, porque é similar aos outros procedimentos mecânicos empregados nos serviços de abastecimento de água; e perene, porque perdura durante toda a vida .

Entretanto, sabe-se que não é a partir do momento em que se colocou o flúor na água que se pode observar os efeitos. Assim, aproximadamente após 10 anos da instalação deste benefício é que seus efeitos serão máximos, uma vez que todas as crianças nascidas daquela data $\mathrm{cm}$ diante terão os dentes de ambas as dentições sob ação do flúor.

A utilização de flúor na água de abastecimento público pode vir a proporcionar uma redução de até $60 \%$ do número de cáric em dentes permanentes, segundo VIEGAS ${ }^{14}$. Outros estudos demonstram que após 10 anos de fluoretação da água, a incidencia de cárie c a mortalidade do $1^{\circ}$ molar permanente diminui sensivelmente na faixa de 9 a 11 anos, de $6,22 \%$ a $44,42 \%$ de dentes em afecção (GUEDES-PINTO, 1996).

A fluoretação das águas de abastecimento já acontece $\mathrm{cm}$ larga escala $\mathrm{cm}$ alguns Estados do Sul e Sudeste do País, sendo que no Estado do Paraná, mais de $90 \%$ da população urbana já pode contar com este benefício.

Outra forma bastante racional de utilização do flúor é através do uso de dentifrícios fluoretados. Pesquisas realizadas em vários países têm demonstrado um declínio da prevalencia da cárie associado ao uso regular destes dentifrícios (SERRA e CURY, 1992) ${ }^{11}$. De acordo com VON DER FEHR e MOLLER 4 (1978), a utilização destes dentifrícios promove uma diminuição da incidência de cárie dentária da ordem de 15 a $30 \%$.

SERRA e CURY'l (1992) afirmam que o efeito anticariogênico do flúor está relacionado à presença do mesmo nos fluidos orais, mesmo em concentrações relativamente baixas. Durante o ato de escovar ou bochechar com dentifrícios fluoretados, o flúor é oferecido à cavidade bucal à semelhança de uma aplicação tópica, porém $\mathrm{cm}$ baixa concentração. Após a utilização de dentifrício e/ou bochecho fluoretados, grande parte do flúor é lixiviado pela saliva e posteriormente deglutido. Entretanto, pequenas quantidades de flúor podem ficar retidas e serem liberadas posteriormente.

Dos métodos de aplicação tópica, a utilização de dentifrícios fluoretados talvez seja o de maior alcance, principalmente devido à intensa propaganda difundida pelos meios de comunicação de massa (CURY et al., $1981)^{3}$.

GEIA6 $^{6}$ (1989) argumenta que, em 1988, somente o segmento industrial correspondente aos dentifrícios rendeu cerca de US\$188 milhões com a venda de 54.500 toneladas, o equivalente a 900 milhões de tubos $e$ consumo "per capita" de 378 gramas. Isto coloca o Brasil entre os países mais ricos no consumo de dentifrícios.

De acordo com TODESCAN14 (1991), é preciso educar a população para a prevenção e o principal problema está na falta de cultura preventiva que seria constituída por duas ações básicas: escovação e aplicação de flúor.

Como foi mostrado, a população do Brasil, pelo menos em parte, está sendo bem servida em relação ao flúor, seja através da água de abastecimento ou dentifrícios, entretanto, em relação à escovação, tem-se alguns dados alarmantes. Em 1989, eram vendidas no país 70 milhões de escovas por ano. Segundo FERRETRA5 (1996) o consumo de escovas no Brasil é de apenas 90 milhões de unidades por ano, o que é considerado baixo em relação à população de 140 milhões de habitantes, onde o número ideal de consumo seria 600 milhões de unidades por ano.

Diversos trabalhos indicarn que a incidência da cáric dentária está aumentando em países subdesenvolvidos (SMEHHAM, 1984)12, fato contrário ao que está ocorrendo nos países industrializados (desenvolvidos), onde se observa uma diminuição de aproximadamente 40\% no índice de cárie em crianças pré-escolares nos úlímos anos. Segundo SHEIHAM12, o declínio da cárie está associado à água de abastecimento fluoretada, à mais ampla disponibilidade de pastas com flúor, bochechos com flúor, flúor sistêmico, modificações no padrão e quantidade de consumo de açúcar e possivelmente com o uso de antibióticos. Entretanto, o único denominador comum entre os países que observaram o declínio foi o aumento do uso de dentifrícios fluoretados.

No Brasil, sabe-se que a prevalência de cáries vem 
diminuindo nos centros Urbanos (ABOPREV, 1996) ${ }^{1}$, embora a extensão dessa mudança seja difícil de se avaliar. Em uma região de aproximadamente $8000 \mathrm{~km}^{2}$, no Norte do Estado do Paraná, MORITA ${ }^{7}$ et al. (1995) observaram uma grande variação regional na prevalência de cáries em escolares de 12 anos, em 16 municípios. Em Londrina, cenário desta pesquisa, observa-se o melhor ganho em saúde bucal de sua região, sendo que o CPOD aos 12 anos em 1981 cra de 6,95 passando para 3,1 em 1995. Provavelmente, diversos fatores concorreram para que esse declínio pudesse ser observado. Entretanto, pouco se sabe sobre a extensão do método preventivo a nível individual, ou scja, a utilização de escovas e dentifrícios luorctados como aliados nesse processo, desde que as marcas de dentifrícios mais consumidas foram lluoretadas. Um dos objetivos do presente trabalho foi verificar se, mesmo em uma população de baixa renda, a escovação e o uso de dentifrícios fluoretados, por sua freqüência de utilização, poderiam ser incluídos entre os fatores a se ponderar na análise do ocorrido. Além disto, buscou-se através de pesquisa domiciliar, identificar indicadores do conhecimento da população sobre higienc bucal.

\section{MATERIAIS E MÉTODOS}

\subsection{População e Amostra}

A população do presente estudo foi composta de 50 crianças na faixa elária de 11 a 12 anos residentes nos conjuntos União da Vitória e suas respectivas mães. A amostra foi arbitrariamente dimensionada visando aplicar o questionário em uma população de baixa renda. A região sul de Londrina abriga uma das maiores concentrações urbanas de população extremamente pobre. São aproximadamente 11.000 pessoas que vivem nos conjuntos União da Vitória I, II, III, IV e V. Esta área apresenta as piores condições de saúde e também o pior Coeficiente de Mortalidade Infantil da cidade de Londrina (SILVA, 1992) ${ }^{13}$.

A amostra final, considerando que algumas mães não foram encontradas em repetidas visitas domiciliares, foi constituída por 39 crianças (chamadas de grupo F1) e 39 mães (chamadas de grupo Ml).

\subsection{Coleta de Dados}

Os dados foram coletados através de questionários aplicados em duas etapas: nas crianças, a escola local foi utilizada como área de apoio. Para as mães, a escola forneceu os endereços e os questionários foram aplicados pelo autor em 4 visitas domiciliares. No que diz respeito ao uso de dentifrícios e escova dental, o entrevistador solicitou que ambos fossem mostrados afim de evitar um viès resposta-rcalidade.

O cxame clínico para determinar a experiência ou não de cárie nas crianças foi realizado por um examinador, através de inspeção visual, sob luz natural c utilizando espátula de madeira para afastamento dos tecidos moles, sendo empregada a técrica de estimativa rápida. O critério de presença de cáric foi o adotado pela OMS (1988).

\subsection{Análise dos Dados}

Foi realizado o tratamento estatístico visando comparar os dois grupos (F1 c M1) através do teste do $\mathrm{Chi}^{2}$, utilizando para isso o programa Epidat (OPAS, $1994)^{8}$.

\section{RESULTADOS E DISCUSSÃO}

\subsection{Caracteristicas da Amostra}

\subsubsection{Grau de escolaridade da mãe}

Com relação ao item grau de escolaridade da mãe, 33 (84.62\%) das mães (grupo M1) têm algum nível de instrução e apenas $6(15.38 \%)$ afirmam não ter estudado.

A tabela 1 mostra a predominância de mães com $1^{\circ}$ grau incompleto $(87.9 \%)$ e que apenas $4(12.1 \%)$ concluíram o $1^{\circ}$ grau.

Apesar da população estudada ser de uma região extremamente carente, observa-se que $84.62 \%$ da mães tiveram algum tipo de estudo e isto pode estar refletindo diretamente na educação de seus filhos. 
TABELA 1 - Grau de escolaridade das mães entrevistadas. Conjuntos União da Vitória, Londrina, 1996

\begin{tabular}{l|c}
\hline Escolaridade & $(\mathbf{N})$ \\
\hline não cstudou & 6 \\
\hline $1^{\circ}$ grau incompleto & 29 \\
\hline $1^{\circ}$ grau completo & 1 \\
\hline $2^{\circ}$ grau incompleto & 2 \\
\hline $2^{\circ}$ grau completo & 1 \\
\hline
\end{tabular}

\subsubsection{Níveis de Renda}

A tabela 2 indica que no grupo en estudo, a renda predominante é de 1 salário mínimo $(41.02 \%)$ e que as familias com renda acima de 3 salários mínimos representam apenas $10.26 \%$ da amostra.

TABELA 2 - Renda familiar das famílias entrevistadas. Conjuntos União da Vitória, Londrina, 1996

\begin{tabular}{l|c}
\hline Renda & $(\mathrm{N})$ \\
\hline até 1 salário & 16 \\
\hline I a 2 salários & 7 \\
\hline 2 a 3 salários & 12 \\
\hline mais de 3 salários & 4 \\
\hline TOTAL & 39
\end{tabular}

\subsubsection{Frequiência de cárie nas crianças estudadas}

Com relação a frequiência de cárie, os resultados mostram que as crianças sem cárie representam $43,6 \%$ da amostra c somente 5 (12.82\%) das crianças têm 3 ou mais cáries presentes (Tábela 3). Comparados com o dado disponível para Londrina, onde apenas $20 \%$ das crianças nessa faixa etária estão livres de cárie (MORITA et al, 1995), este estudo indica que, mesmo frente às dificuldades financeiras e necessidades dos grupo $\mathrm{cm}$ questão, está ocorrendo uma baixa na freqüência de cárie nesta região.
TABELA 3 - Frequiência de cáric dentária dos escolares examinados. Conjuntos União da Vitória, Londrina, 1996

\begin{tabular}{lc|c}
\hline Freqüência & $(\mathbf{N})$ & $\mathbf{f}(\%)$ \\
\hline sem cárie & 17 & 43.58 \\
\hline 1 dente cariado & 7 & 17.94 \\
\hline 2 dentes cariados & 10 & 25.64 \\
\hline 3 dentes ou mais & 5 & 12.82 \\
\hline
\end{tabular}

\subsection{Respostas ao Questionário}

\section{Você possui uma escova de dentes?}

A totalidade das crianças (100\%) afirma possuir escova de dentes e entre as mães a resposta predominante foi a de que possuíam escova de dentes $(92.30 \%)$. No conjunto, $96 \%$ dos entrevistados informaram possuir escova dental, como mostra a figura 1.

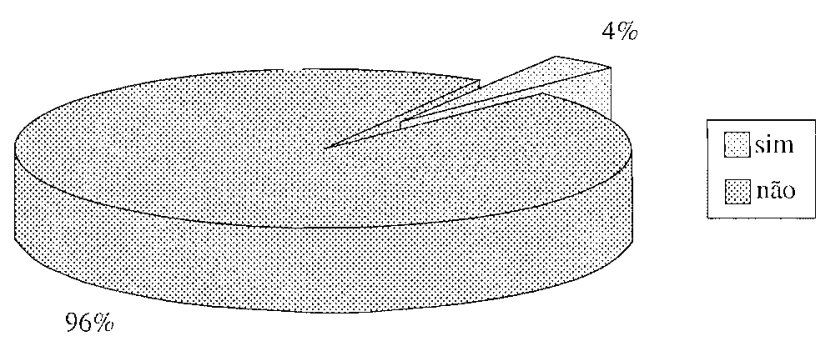

FIGURA 1 - Respostas à pergunta: "Você possui uma escova de dentes?" - Conjuntos União da Vitória, Londrina, 1996

Estes dados contrariam a idéia de que a população mais carente não se preocupa com a higienc bucal. Apesar do consumo de escovas dentais, no Brasil, estar bem abaixo do ideal, conforme afirma FERREIRA 5 (1996), nesta população, apesar das necessidades sócioeconônicas, somente $7.7 \%$ das mães ( $3.84 \%$ do total) 
afirmam não ter escova de dentes e se justificam pelo fato de serem desdentadas totais.

\section{Usa pastas de dentes?}

Assim como o uso das escovas (questão 1), 100\% das crianças afirmam usar creme dental para escovar os dentes. O número se repete também para as mães, onde $100 \%$ das mães que usam escova dental $(92,31 \%$ do total) escovam seus dentes com o auxílio de dentifrícios. Estes dados concordam com GEIA6 (1989) quando afirma que o Brasil está entre os países mais ricos no consumo de dentifrícios. Sendo assim, a baixa freqüência de cárie observada nestas crianças pode estar relacionada ao uso de dentifrícios, dados que concordam com CURY2 (1996) quando afirma que os dentifrícios existentes no mercado brasileiro contêm flúor em condiçôes de interferir com o desenvolvimento da cárie. Esses resultados indicam que o uso de dentifrício fluoretado deverá estar incluído entre os métodos preventivos de massa quando da análise das razões explicativas do declínio de cárie observado na população Iondrinense. O sucesso dependerá do seu uso individual, mas principalmente coletivo, nos Programas de Saúde de responsabilidade dos Órgãos Públicos.

\section{Quanto tempo dura uma escova de dentes?}

A maioria das crianças $(51,29 \%)$ concorda em dizer que um escova de dentes dura aproximadamente um mês. Já para $28,20 \%$ a escova dura em torno de seis meses e $7,70 \%$ dizcm que a escova dura três meses. Para $12,82 \%$ das crianças a escova dura mais de um ano.

As mães concordam, em sua maioria (52.77\%) que o tempo de vida ideal de um escova de dentes é em torno de seis meses c para $36.11 \%$ este tempo é de 2 a 3 meses. O mesmo número de mães (5.56\%) acredita que o tempo de vida de uma escova de dentes é de um mês ou vários anos. Esses dados demonstram o total desconhecimento da população estudada no que se refere ao tempo de vida útil de uma escova dental, o que pode ser observado na figura 2.

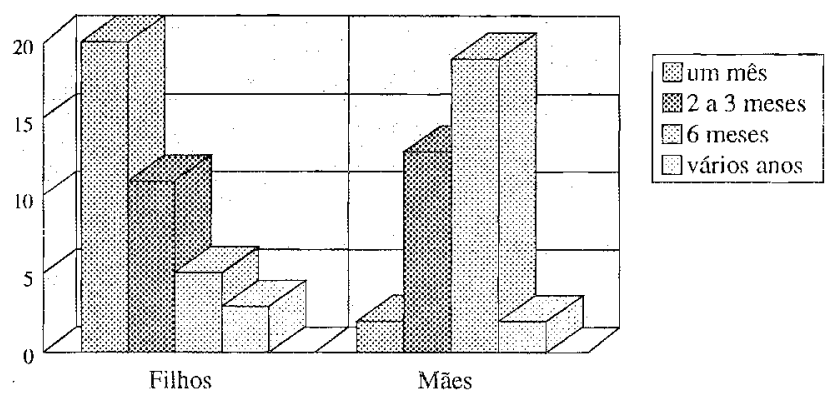

FIGURA 2-Respostas à pergunía: "Quanto tempo dura uma escova de dentes?" - Conjuntos União da Vitória, Londrina, 1996.

\section{Cono escolhe a pasta de dentes?}

Quando a questão é como escolhe a pasta de dentes, o critério de escolha é significativamente diferente enire mães e filhos (Chi2 17.68, $p=0.0000262$ ), sendo que o gosto do dentifrício aparece como principal resposta das crianças $(58.97 \%)$ e a marca aparece como principal resposta das mães $(61.11 \%)$, indicando um comportamento ligado ao estímulo de consumo.

\section{Quantas vezes por dia você escova?}

A figura 3 mostra que escovar os dentes 3 vezes por dia está se tornando um hábito para a maioria das crianças estudadas $(76.92 \%)$ e esta também foi a resposta mais citada pelas crianças livres de cárie (80.00\%). Outro dado importante é que nenhuma criança escova os denies apenas uma vez ao dia, ao contrário das mães que, em sua maioria, escovam os dentes de uma a duas vezes por dia $(55.6 \%)$. Embora tenha que se considerar a possibilidade de viés questionário/realidade, estes dados indicam que está ocorrendo uma mudança no comportamento da população no que se refere a higiene bucal. 


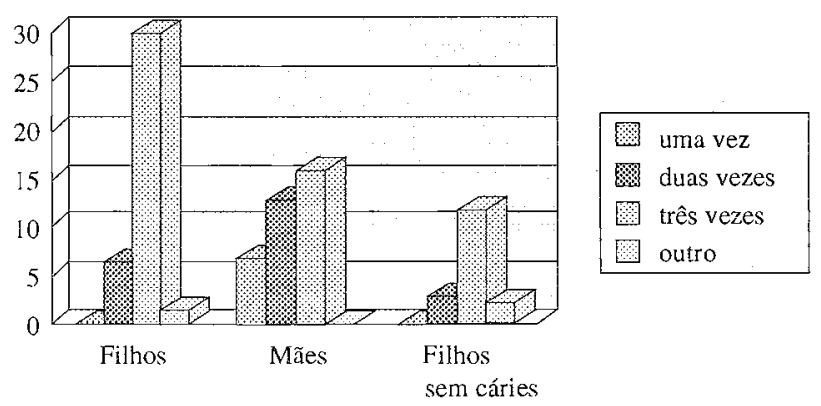

FIGURA 3 - Respostas à pergunta: "Quantas vezes por dia você escova os dentes?" - Conjuntos União da Vitória, Londrina, 1996.

\section{Quanto tempo dura a escovação?}

Em relação ao tempo de escovação, 79,49\% das crianças estudadas afirmaram escovar os dentes por um tempo de 1 a 2 minutos ou mais sendo que apenas $20,51 \%$ o fazem por menos de um minuto. Contudo, exatamente $50 \%$ das mães relatam escovar por menos de un minuto. Quando analisamos esta questão de acordo com o grau de escolaridade da mãe, observamos que o tempo de escovação aumenta conforme a escolaridade. Das mães que nunca estudaram, 5 (83.33\%) escovam os dentes por menos de 1 minuto e todas afirmam escovar de uma a duas vezes ao dia (questão 5). Ao contrário, as mães com algum grau de instrução afirmam escovar por mais tempo (56.66\% por 1 a 2 min. ou mais de $2 \mathrm{~min}$ ) e um maior número de vezes ao dia ( $53.33 \%$ responderam que escovam 3 vezes ao dia).

Estes dados nos revelam mais uma vez que esta ocorrendo uma mudança no comportamento desta população quando se trata da importância da escovação e do tempo em que esta deva ser realizada. O tempo de escovação entre mães e filhos mostrou-se significativamente diferente ( $\mathrm{Chi}^{2} 7.19, \mathrm{p}=0.0073449$ ). A figura 4 apresenta a distribuição de respostas à pergunta: "Quanto tempo dura a escovação?".
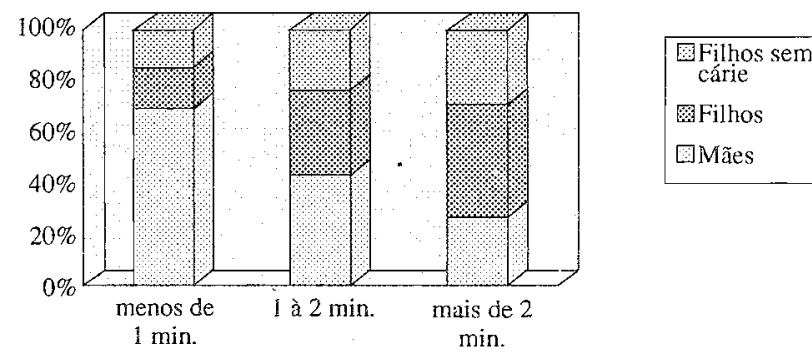

FIGURA 4 - Respostas à pergunta: "Quanto tempo dura a escovação?"- Conjuntos União da Vitória, Londrina, 1996.

7. Os seus pais conversaram com você sobre a importancia da escovação?

Esta questão mostra mais uma vez a importância da educação para a prevenção e para a mudança de comportamento. Ao analisarmos os dados, temos que 89.74\% das crianças receberam orientação dos pais sobre a importância da higiene bucal e entre as crianças livres de cárie (17), apenas duas não receberam orientação. Entre as mães, $72.22 \%$ nunca receberam este tipo de informação, o que mostra uma diferença bastante significativa em relação a mudança de comportamento de uma geração para outra (Chi2 26.66, p=0.0000002) (Figura 5).

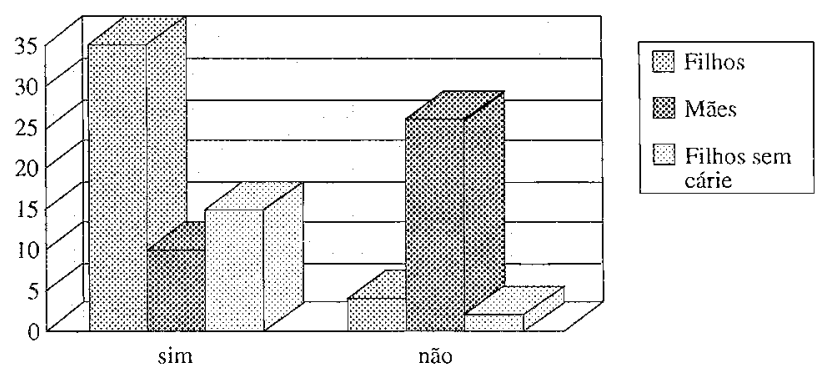

FIGURA 5 - Respostas à pergunta: "Os seus pais conversaram com você sobre a importância da escovação?"- Conjuntos União da Vitória, Londrina, 1996. 


\section{Por que escova os dentes?}

$\mathrm{O}$ aspecto educativo traz a idéia de modificação e a tabela 5 dcmonstra que está ocorrendo uma modificação no aspecto da higiene bucal. As crianças se preocupam mais com a limpeza dos dentes $(59.0 \%)$ do que com o bom hálito $(25.64 \%)$ ou outros motivos (15.38\%).

As mães se preocupam também com a limpeza dos dentes, porém em uma menor porcentagem (36.11\%). Outra característica importante é que $30.55 \%$ das mães escovam os dentes para que não estraguem e outras $13.9 \%$ o fazem puramente por uma questão de higiene. A resposta outros citada nos dois grupos refere-se a: "para ficarem brancos; para não doer; para não dar problema no estômago ou porque aprendeu".

Estes resultados mostram que as populações (mães e fïlhos) são significativamente diferentes quando se trata do porquê da escovação ( $\mathrm{Chi}^{2} 4.22, \mathrm{p}=0.0287795$ ).

TABELA 5 - Respostas à pergunta: "Por que você escova os dentes?" - Conjuntos União da Vitória, Londrina, 1996

\begin{tabular}{l|c} 
Filhos & $(\mathbb{N})$ \\
\hline dar bom hálito & $\frac{10}{23}$ \\
\hline limpar os dentes & 6 \\
\hline outros & \\
\hline Mães & 3 \\
\hline dar bom hálito & 13 \\
\hline limpar os dentes & 11 \\
\hline para não estragar & 5 \\
\hline higiene & 4 \\
\hline outros &
\end{tabular}

9. Alguma vez alguém orientou você a escovar os dentes?

A pergunta "alguma vez alguém orientou você a escovar os dentes?"

evidencia uma nítida mudança de comportamento com predominância de $100 \%$ de crianças que responderam sim. Contrário a isto, está a resposta das mães onde prcdominam as respostas negativas (61.53\%) sendo uma diferença bastante significativa ( $\mathrm{Chi}^{2} 34.67$, $p=0.0000000$ ) (Figura 6).

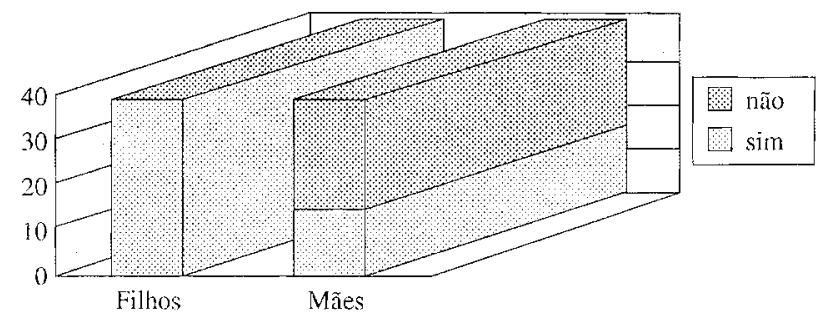

FIGURA 6- Respostas à pergunta: "Alguma vez alguém orientou você a escovar os dentes?".

Quando perguntamos quem ensinou, observamos que o dentista representa $38.46 \%$ das respostas das crianças, outras $25.64 \%$ foram orientadas na escola ou pelas mães $\mathrm{c}$ somente $10.25 \%$ disseram que aprenderam através da televisão. Entre as 15 mães que responderam sim, apenas 4 foram orientadas pelo dentista, 3 aprenderam na escola, 6 aprenderam com as mães e 2 com os próprios filthos, conforme nostra a figura 7 .

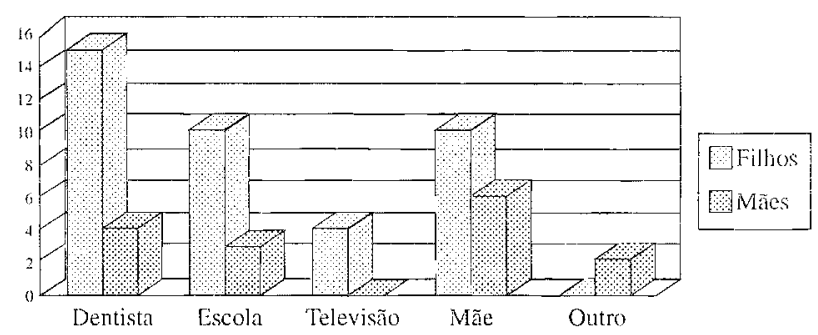

FIGURA 7 - Respostas à pergunta:"Quen ensinou você a escovar os dentes?"

Esse resultado demonstra a necessidade de se expandir a orientação sobre higicne bucal para a população adulta. Embora as crianças estejam recebendo informações seja pela escola, mídia, ou serviços 
municipais de saúde e em alguns casos, transmitindo esses novos conhecimentos a seus familiares, os adultos parecem estar sendo claramente negligenciados. Além disto, o questionário não pôde avaliar outras fontes de informação como por exemplo o rádio, cujo alcance é superior à televisão nessa população.

De toda forma, no que diz respeito a instrução de higiene, fica evidente a lacuna existente entre as duas geraçôes, o que pode estar implicado na mudança de perfil epidemiológico observado na população estudada.

\section{CONCLUSÕES}

Considerando-se a população do presente estudo, pode-se concluir que:

1) A população estudada, apesar das dificuldades financeiras, se preocupa com a higiene bucal e usa para isso, escovas dentais e dentifrícios fluoretados, sendo que este pode ser considerado como método preventivo de massa, dada a sua ampla utilização ( $100 \%$ das crianças e $92.3 \%$ das mães cntrevistadas). As condições que podem melhorar a eficácia do método em questão, como os aspectos qualitativos de escovações (nível individual de higienização alcançado) não foram avaliados no presente trabalho. Isso poderia clarificar aspectos importantes ligados ao tema, abrindo perspectivas para novas pesquisas.

2) O grupo Fl higieniza mais vezes e por mais tempo que o grupo M1, demonstrando uma nítida mudança de comportamento de uma geração para outra. Além do fato de higienizarem, em sua maioria, visando a limpeza dos dentes e ñ̃o se preocupando em não sentir dor ou ter problemas no estômago, como argumenta uma parcela do grupo $\mathrm{Ml}$.

3) O grupo Fl é mais assistido no que diz respcito ao acesso às informações sobre higiene bucal que o grupo M1. Esse fato torna evidente a necessidade de se centrar esforços na população adulta, sobretudo se considerarmos que estes são multiplicadores em seus lares. Há que se considerar ainda que $61.53 \%$ das mães entrevistadas nunca recebcram qualquer lipo de informação a respeito de higiene bucal.

\section{REFERÊNCIAS BIBLIOGRÁFICAS}

1. ABOPREV. O Brasil não é mais o campeão mundial de cárie, Jornal da ABOPREV,mar/abr 1996.

2. CURY, J.A. Dentifrícios fluoretados no Brasil; Jornal da $A B O P R E V$, ano VII,p.3, maio/jun, 1996.

3. CURY, J.A. GUIMARÃES, L.O.C., et al, Análise de dentifrícios fluoretados: concentração e formas químicas de fluoretos encontrados em produtos brasileiros, Revista da APCD, v.35, n.2, p.142147,mar/abr, 1981.

4. FEHR, F.R. von der; MOLLER, I.J. Caries-preventive fluorides dentifrices. Caries Res., 12 (supl.1): 31-7, 1978

5. FERREIRA, R.A. Driblando a cárie, Revista da APCD, v.50, n.1, p.8-20, jan/fev, 1996.

6. GEIA, A.M. Dentes rendem milhões às Industrias. $O$ Estado de São Paulo, Economia \& Negócios, p.12, 22 de setembro de 1989.

7. MORITA, M. C.; GUTIERREZ, M. C.; HILle, A. L. Cárie dentária em escolares da zona urbana e rural da $17^{\mathrm{a}}$ Regional de Saúde do Paraná: Declínio de prevalência e variações regionais. In.: Congresso Latino-americano de Epidemiologia,1,1995. Anais, Salvador, 1995.

8. OMS(Organização Mundial de Saúde). Enquêtes sur la Santé Bucco'dentaire- methodes fondamentales. Genève, OMS,3e., 1988, 60p.

9. ORGANIZACIÓN PANAMERICANA DE LA SALUD (OPAS) EPIDAT: Análisis Epidemiológico de Datos Tabulados. Organizacion Panamericana de la Salud: Xunta de Galicia. Washington, 1994.

10. PINTO, V.G. Índice de cárie no Brasil c no Mundo, Revista Gaúcha de Odontologia, v.44 (1), p.8-12, jan/fev, 1996.

11. SERRA, M.C.; CURY, J.A. Cinética do Flúor na saliva após o uso de dentifrícios e bochecho fluoretados, Revista da APCD, v.46, n.5, p.875 - 878, set/out, 1992.

12. SHEIHAM, A. Changing Trends in Dental Caries, Int.J.Epidemiol, v.13, n.2, 1984.

13. SILVA, S. F.(org). Rumos da saúde para Londrina: Plano municipal para o biênio 96-98. Londrina, Midiograf, 1996. 232p.

14. TODESCAN, J.H.; SIMA, F.T. Campanhas de Prevenção e Orientação para a Higiene Bucal: Prevenção: Usos e Costumes da Higiene Bucal I, Revista da APCD, v.45, n.4, p.537-539, jul/ago, 1991.

15. TODESCAN, J.H. Usos e costumes da higicne bucal II, Revista da APCD, v.45, n.5, p.593-596, set/out, 1991. 